Rev. Saúde públ., S. Paulo

2(2) :216-225, dez. 1968.

\title{
O PROBLEMA METODOLÓGICO EM EDUCAÇÃO SANITÁRIA (1)
}

André Francisco PILON

\begin{abstract}
Em qualquer programa social, de parte de órgãos públicos ou privados, coloca-se a questão de como coordenar as relações agência-clientela, de maneira a harmonizar a política e os objetivos da agência com os interêsses e necessidades da clientela. LTWWAK \& MEYER, 1 postularam que essa coordenação é função da distância social correta entre agência-clientela. Assim, para que os objetivos da agência sejam alcançados, tendo em vista uma «resposta» da clientela, é necessário criar e manter entre ambas uma distância tal que nem venham a se confundir (identificação), nem percam de todo o contacto (isolamento). Essa distância «ideal» seria criada e mantida pela aplicação, discriminada, de uma série de mecanismos de enlace, diferentes em iniciativa, intensidade, perícia e cobertura (perito participante, líder natural, agência local, associação voluntária, mensageiro comum, meios de comunicaç̃̃o social, autoridade formal, e função delegada). Assim, conforme a distância social pré-existente (que implica em definir o grau de acôrdo ou desacôrdo entre a agência e a clientela, no tocante a atitudes e valores), os objetivos do programa (que implica em analisar o conteúdo da mensagem a ser levada à clientela, que pode ir de simples informação até a mudança de padrões culturais) e, ainda, as caracteristicas burocráticas da agência interessada (que devem ser adequadas ao tipo de trabalho a ser realizado, dado às limitacões inerentes às diferentes estruturas), poderemos aplicar determinados mecanismos de coordenação, com probabilidades de êxito previstas para os diferentes casos. Acreditamos que a preconizala integração das Ciências Sociais, Fducacionais e Administrativas encontra na «teoria de equilíbrio» para coordenação agência-clientela, proposta pelos autores citados, estimulante contribuição para conseguir resultados práticos. Em relação à metodologia da Educação Sanitária, representam os mecanismos de enlace diferentes métodos, cuja escolha, na implementação do componente educativo dos programas de saúde pública, fica bastante facilitada pelos critérios propostos por LTTWAK \& MEYER 1.
\end{abstract}

Sabemos que a apreciação isolada dos métodos de educação sanitária, sem levar em conta os objetivos do programa, a agência que o executa e a clientela à qual se destina, não nos permite, de antemão, eleger o "melhor método" para todo e qualquer programa.

No entanto, determinada a agência, especificada a clientela e assentados os obje- tivos do programa, já será possível distinguir, com razoável segurança, o método ou os métodos mais adequados.

0 conceito de "rendimento ótimo", resultante do "esfôrço mínimo" mais "resultado e satisfação máximos" (2) aplica-se também à metodologia utilizável nos programas de educação sanitária. Isto é, para cada programa, para cada agência,

Recebido para publicação em 28-8-1968

(1) Da Disciplina Autônoma de Educação Sanitária, da Faculdade de Higiene e Saúde Pública da USP. Apresentado no simpósio "Educação, um dos componentes essenciais dos programas de saúde", como parte das "Sessōes de Educação Sanitária”, realizadas de 5 a 9 de fevereiro de 1968, na Faculdade de Higiene e Saúde Pública da USP.

(2) Princípio de racionalização do trabalho. 
PILON, A. F. - O problema metodológico em educação sanitária. Rev. Saúde públ., S. Paulo, 2(2) :216-225, dez. 1968.

para cada comunidade devemos escolher um enfoque metodológico adequado ao exato alcance dos objetivos propostos. Vejamos agora como êsse rendimento ótimo pode ser expresso em têrmos de "distância social", ou, em outras palavras, é necessário buscar um equilibrio adequado nas relações agência-cliente, de forma a manter a correta distância, evitando tanto que uma e outro andem à deriva, como que se confundam numa coisa só (Fig. 1).

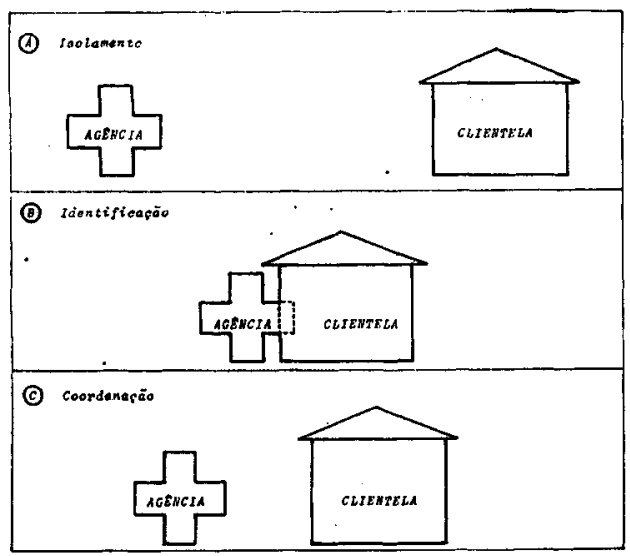

Fig. 1 - Três tipos possiveis de distância social agência-clientela.

Tipo A - Isolamento. Distância social demasiada. Ausência de comunicação. Objetivos isolados ou conflitantes. Programa fracassado. Mau equilibrio agência-clientela.

Tipo B - Identificagão. Distância social quase nula. Comunicaçāo subjetiva. Objetivos confusos ou confundidos. Programa fracassado. Mau equilíbrio agência-clientela.

Tipo C - Coordenação. Distância social correta. Comunicação adequada. Objetivos atingidos em comum. Programa bem sucedido. Bom equilíbrio agência-clientela.

Exemplifiquemos. As associações de 'pais e mestres representam um "mecanismo de enlace", entre a escola e a comunidade, susceptível de criar e manter uma distância correta tal que nem pas- sem os pais a "morar" na escola, nem a ela jamais compareçam. Ambos os extremos seriam prejudiciais.

No entanto, poderá ocorrèr que a escola esteja situada numa comunidade onde a "associação de pais e mestres" deverá ser implementada por outro ou outros mecanismos de enlace cujo poder de iniciativa, intensidade de ação, perícia e cobertura sejam maiores do que as associações voluntárias. E o caso da comunidade indiferente ou hostil aos objetivos da agência escolar, ou sanitária, ou de extensão agrícola, etc.

Aqui entra a contribuição de dois estudiosos, Litwak \& Meyer ${ }^{1}$ que, reconhecendo variar a distância social entre as organizaçōes burocráticas incumbidas de prestar serviços à comunidade e o ambiente social em que operam, formularam uma teoria de equilíbrio para coordenação agência-clientela, fornecendo um critério para decidir quais os mecanismos de enlace susceptiveis de aumentar a comunicação entre os grupos envolvidos, no caso de grande distância social, manter $a$ comunicação existente, quando a distância é correta entre os grupos e até diminui-la, quando a distância social é mínima (1).

E uma contribuição valiosa porque combina os achados da Ciência da Administração, através do estudo da natureza (estrutura e dinâmica) das agências, das Ciências Sociais, pela análise dos grupos da comunidade (características e comportamento) e pesquisa dos princípios de comunicação envoltos e os das Ciências Educacionais, que os utilizam no processo de mudança.

\section{Natureza das Agências:}

Os autores citados distinguem, bàsicamente, 4 modelos de organização burocrática:

(1) Segundo LITWAK \& MEYER, existe um ponto ótimo, aquém ou além do qual afetamos o contrôle social, produto da distâncla correta entre as organizações burocrátícas e os grupos primários externos. Para que suas funções soclais se complementem e harmonizem é necessário relacioná-los, porém sem confundi-los ou identificá-los. 
PIION, A. F. - O problema metodológico em educaçáo sanitária. Rev. Saúde públ., S. Paulo, 2(2) :216-225, dez. 1968 .

- o racional-legal, caracterizado por relações impessoais, normas específicas (geralmente codificadas), estrita hierarquia de autoridade, especialização de funções, definição rígida de direitos e deveres e avaliação na base do mérito;

- o de relações humanas, caracterizado por relações pessoais, normas gerais, ou como dizem, em inglês, "general policies", relação de camaradagem entre colegas, ampla definição dos objetivos da organização e avaliação na base do mérito (exceto quanto à última, as características do modêlo de relações humanas opõem-se ao racional-legal);

- o profissional, resultante da combinação dos dois anteriores, incorporando, através de estruturas paralelas de autoridade e departamentos autônomos, características racionais-legais e de relações humanas, e finalmente;

- o paternalista, caracterizado pelo nepotismo, ênfase em objetivos pessoais e não empresariais, política discriminatória na base das amizades pessoais, preconceitos, estereotipos etc., com ausência completa da avaliação por mérito. É o que, no Brasil, se chama de intervenção polí- tica na criação e funcionamento das agên. cias e de certa forma retrata uma forma de paternalismo ${ }^{(1)}$. Enquanto o modêlo paternalista é positivamente inadequado, o profissional possibilita lidar com uma ampla gama de eventos, tanto os que recorrem (especialidade do racional-legal), como os que não recorrem (especialidade do modêlo tipo relações humanas), combinando perícia e flexibilidade, cobertura ampla e ação rápida e intensa ${ }^{(2)}$ (Figura 2).

\section{Análise dos Grupos:}

Os grupos primários externos à agência, tais como a família e a vizinhança, distinguem-se pelo contacto face a face, permanência de relações, comunicação difusa e multitemática (pode-se falar de tudo...) e não instrumentalidade (a amizade é um fim em si e não instrumento para conseguir algo).

Em relação aos objetivos da agência podem ser resistentes, conformes ou mistos. Serão resistentes se seus valores se opõem aos da agência e estão organizados de forma a resistir aos esforços daquela. Serão conformes se partilham dos

(1) No Brasil coexistem, dentro de uma estrutura racional-legal, tanto modelos paternalistas como estatutários. As normas e regulamentos deixam muitas vêzes de serem aplicadas nos casos influentes politica e económicamente, passando a ser instrumento de díscriminação social e escudo para não enfrentar os problemas sociais. Por outro lado processou-se uma curiosa assimilação do modêlo de relações humanas pela estrutura burocrática racional-legal. Passou-se a fazer relações humanas por decreto. Dispositivo do Regimento Interno dos Grupos Escolares (Estado de São Paulo) reza: "A disciplina escolar há de repousar essencialmente na afeição que diretor, professôres e funcionários devem dedicar aos alunos de modo a serem estes dirigidos mais pelos conselhos e persuasão amistosos". (Art. 42). Outro exemplo? Projeto de reforma do Código de Menores, apresentado à Câmara dos Deputados, em 1952, pelo representante do Amazonas (Sr. André Araújo), continha artigos como éstes: Art. 341 - Os passeios sempre devem ser feitos pela manhā, ao sol. Art. 422 - Quando, num menino, a conduta má se repete freqüentemente, é sinal de que o professor está fracassando na sua missäo. Art. 454 e preciso ter confiança no aluno.

(2) LITWAK citado por LITWAK \& MEYER 1, considera que a estrutura e o sucesso da emprêsa estão relaclonados, em parte, à natureza dos objetivos que persegue e à natureza das tarefas executadas para atingi-los. Quando os objetivos são relativamente claros, os critérios para alcançá-los razoảvelmente determinados, e as tarefas, padronizadas, se repetem, a estrutura racional-legal descrita por Max Weber emerge e torna-se suficiente. Por outro lado, se os objetivos são ambigüos, os critérios incertos e as tarefas não uniformes, o modélo de relaçóes humanas aparece e vinga. Finalmente, quando há uma mistura de tudo isso, um terceiro tipo, chamado profissional, habilita-se para lidar tanto com situações padronizadas como únicas. $\mathbf{o}$ caso de hospitais, escolas e indústrias empenhadas tanto na pesquisa como na produção. 
PILON, A. F. - O problema metodológico em educação sanitária. Rev. Saúde públ., S. Paulo, 2(2) :216-225, dez. 1968 .

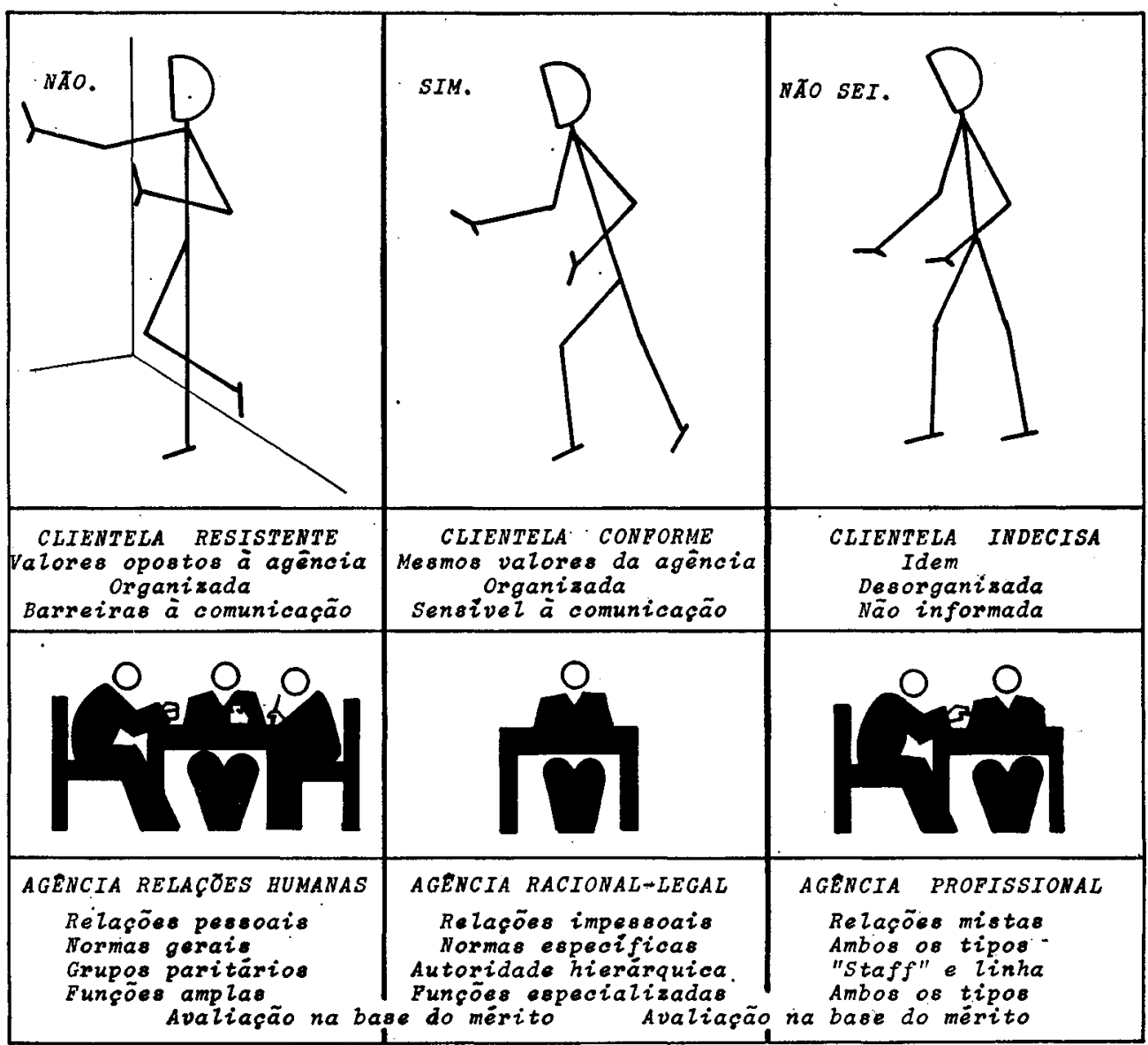

Fig. 2 - Adequação de três diferentes típos de agência a três diferentes tipos de clientela. Clientela Resistente: Agência de Relaçōes Humanas. Clientela Conforme: Agência Racional-Legal. Clientela Indecisa: Agência Profissional.

mesmos valores da agência, estão organizados e predispostos a colaborar com ela. Aqui cabe distinguir os grupos que, embora partilhem dos mesmos valores, ou não estão organizados ou carecem de in. formação suficiente. Finalmente, os grupos mistos apresentam características mistas, embora convivam na mesma área, denotando um fenômeno de não integração social. Os autores definem ainda familias conformes vivendo em núcleos de vizinhança resistentes e famílias resistentes, vivendo em vizinhanças conformes. Os mecanismos de enlace, que veremos a seguir, diferem em cada caso.

\section{Mecanismos de Enlace}

Conhecidas as características das agências e dos grupos que compõem sua clientela, estaremos em condições de escolher o melhor método para atingir os objetivos de nosso programa.

Sua eficiência relativa já é um dado fornecido pelos estudos de psicologia social e pelas ciências educacionais, no tocante aos chamados princípios de comunicação. Assim os mecanismos de enlace utilizados pela agência para influir sôbre os grupos primários, para que adotem os valores e normas por ela preconizados, va- 
PILON, A. F. - O problema metodológico em educação sanitária. Rev. Saúde públ., S. Paulo, 2(2) :216-225, dez. 1968.

T A B E L A 1

Principios de Comunicação e Mecanismos de Enlace entre as Agencias e os Grupos Primários Externos

\begin{tabular}{|c|c|c|c|c|}
\hline \multirow{2}{*}{ Mecanismos de Enlace } & \multicolumn{4}{|c|}{ Principios de Comunicacão } \\
\hline & Iniciativa & Intensidade & Pericia & Cobertura \\
\hline Perito Participante & máxima & alta & máxima & minima \\
\hline Lider Natural & moderada & máxima & baixa & moderada \\
\hline Agencia Local & $\begin{array}{l}\text { moderada } \\
\text { a baixa }\end{array}$ & alta & alta & moderada \\
\hline Associação Voluntária & minima & moderada & moderada & alta \\
\hline Mensageiro Comum & moderada & baixa & minima & máxima \\
\hline Meios de Comunicação Soctal & $\begin{array}{l}\text { alta a } \\
\text { baixa }\end{array}$ & minima & minima & máxíma \\
\hline Autoridade Formal & $\begin{array}{l}\text { alta } a \\
\text { baixa }\end{array}$ & $\begin{array}{l}\text { moderada } \\
\text { a baixa }\end{array}$ & $\begin{array}{l}\text { alta a } \\
\text { baixa }\end{array}$ & $\begin{array}{l}\text { moderada } \\
\text { a baixa }\end{array}$ \\
\hline Função Delegada & alta & $\begin{array}{l}\text { alta a } \\
\text { baixa }\end{array}$ & $\begin{array}{l}\text { alta a } \\
\text { baixa }\end{array}$ & moderada \\
\hline
\end{tabular}

riam em relação à iniciativa, intensidade, pericia e alcance ou cobertura possí. veis a cada um.

$\mathrm{Na}$ prática, quanto maior fôr a distância agência-cliente a cobrir, tanto maior deverá ser a iniciativa desenvolvida pela agência, a intensidade das relações, a perícia ou conhecimento especializado, com maior ou menor alcance ou cobertura (êste últîmo fator varia na razão inversa dos primeiros).

Em se tratando de grupos resistentes, é necessário utilizar um mecanismo cuja iniciativa, intensidade e sofisticação (perícia) seja de tal monta a romper as barreiras de percepção seletiva por êles opostas à ação da agência. Da mesma forma, de acôrdo com os objetivos de nosso programa, teremos mensagens mais ou menos complexas, desde a informação simples a respeito de serviços disponíveis a uma comunidade receptiva até comunica. ções que envolvem mudança de atitudes e comportamento de individuos ou grupos. No primeiro caso poderíamos usar o método de comunicação em massa ("mass-media"), mas, no segundo, sòmente destacando um perito participante, para trabalhar na comunidade, poderemos lograr nossos objetivos (na nomenclatura dos autores, "detached expert approach").

A Tabela 1 nos dá idéia das possibi. lidades dos oito mecanismos de enlace que os autores assinalam como susceptíveis de conseguir, cada um em seu caso, um equilíbrio adequado agência-cliente, coordenando-os para o contrôle social ótimo ${ }^{(1)}$.

\section{Correlações Significantes}

As organizações burocráticas, os grupos primários e os mecanismos de enlace, eis as três variáveis independentes na teo. 

$z(2)$ :216-225, dez. 1968.

ria de LITWAK \& MEYer ${ }^{1}$. E possivel e recomendável, no entanto, correlacioná-las estreitamente em prol de um melhor con. trôle.

Assim, estudadas e definidas as caracteristicas dos grupos primários que constituem nossa clientela e escolhidos os mecanismos de enlace mais adequados a êles, os autores consideram que os resultados seräo melhores quando a estrutura burocrática da agência favoreça a coordenação pretendida ${ }^{(2)}$.

$\mathrm{Na}$ Tabela 2, a hipótese acima é esquematizada. Dados os mecanismos de enlace, sòmente metade será apropriada, respectivamente, para funcionar junto a estruturas racionais-legais ou de relações humanas e, indistintamente, para o modêlo profissional. Quanto maior o algarismo no diagrama, tanto melhor o contrôle ou equilibrio $e$, conseqüentemente, maior a possibilidade de atingir os objetivos do programa.
Verifique-se o menor pêso atribuído ao modêlo racional-legal e respectivos meca. nismos (comunicação em massa, regulamentos e normas etc.), em relação ao "set" de relações humanas, para programas destinados a grupos resistentes e co. mo a situação se inverte no caso de grupos conformes. Veja-se a inutilidade ao empregar mecanismos de enlace próprios de um modêlo de agência junto a outro (Tabelas 3 e 4).

$\mathrm{Na}$ Tabela 5 os grupos primários são estudados mais profundamente e classificados segundo dois diferentes níveis, o de vizinhança, e o das famílias que a integram. Os autores não mencionam, expressamente, o nível mais amplo de comunidade, mas, pessoalmente, acreditamos que dêle se aproximam bastante.

A análise do diagrama revela-nos que os resultados melhores serão alcançados pela correta combinação das três variáveis estudadas. Nos casos de equivalên-

(1) Perito Participante ("Detached Expert Approach"), profissionais com autonomia para fazer decisões no campo, através de participacão direta nos grupos, dos quals ganha a confiança. Exemplo: Trabalhadores Sociais com grupos de delinqüentes, Organizadores de Comunidade. í um mecanismo caro. Lider Natural ("Opinion Leader Approach"), elemento da propria comunidade, susceptivel de influir em seus membros pelo prestigio e conflança que desfruta. Agência Local ("Settlement House Approach") operando dentro da comunidade, mas dependendo da receptividade da populaça para executar seus programas. Exemplo: Centro de Saúde, Centro Comunitário. Associacão Voluntária ("Voluntary Association Approach"), reunindo membros da agência e da clientela. Ex.: Associação de Pais e Mestres. Mensageiro Comum ("Common Messenger Approach"), pertencendo tanto à agência como à clientela. Ex.: Escolares. A posição do mensageiro na hierarquia de ambos os grupos influirá na eficácia da mensagem. Meios de Comunicação - Social ("Mass-media Approach"), como o rádío, a televisão, a imprensa. Sua intensidade pode ser aumentada, utilizando os idolos da juventude (se a êles se destina nossa mensagem), os líderes de opiniāo públíca etc. Sua perícia, também, desde que assessorados por especialistas. Autoridade Formal ("Formal Authority Approach"), ou comunicaçāo por leis e decretos, policiando sua execução. Ex.: Polf́cia, Serviço Sanitário (antigamente). Função Delegada ("Delegated Function Approach"), em que outras agências, mais especializadas e com melhor acesso à clientela, levam a mensagem, atuando como elo entre a agência original e a população. Ex.: Escolas, educando sôbre normas de trânsito, igrejas, apoiando campanhas sociais etc.

(2) Veja-se a consequiencia danosa para o ensino nacional na adoção, pela escola brasileira, de principios da escola nova, sem modificar sua estrutura racional-legal e paternalista tradicional. Embora defenda técnicas de ensino modernas, mantém uma organização obsoleta, que opõe resistência entre teoria e prática. De acôrdo com recente trabalho de PEREIRA 2, por disciplina os professôres entendem "um tipo de submissāo das criancas aos adultos, principalmente aos professôres e diretor, onde se conglomeram padrőes de comportamento, valores e atitudes típicos de organizaçōes tradicionalistas: "respeito" diante dos adultos, acatamento total de suas decisōes, tratamento reverencial e mesmo temeroso, infbição da vida social espontanea infantil, "reconhecimento" para com o professor etc". 
PILON, A. F. - O problema metodológico em educacão sanitária. Rev. Saúde públ., S. Paulo, 2(2) :216-225, dez. 1968 .

T A B E L A 2

Equilibrio otimo entre a Estrutura Burocrática da Agência, os Mecanismos de Enlace e os Grupos Primários Externos

\begin{tabular}{|c|c|c|c|c|}
\hline \multirow[b]{2}{*}{$\begin{array}{c}\text { Estrutura Burocrática da } \\
\text { Agência: Modelos }\end{array}$} & \multirow[b]{2}{*}{ Mecanismos de Enlace } & \multicolumn{3}{|c|}{ Grupos Primários } \\
\hline & & 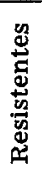 & 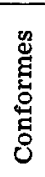 & 量 \\
\hline De Relacões Humanas & $\begin{array}{l}\text { Líder Natural } \\
\text { Agência Local } \\
\text { Perito Partícipe } \\
\text { Função Delegada }\end{array}$ & $\mathbf{5}$ & 3 & 3,5 \\
\hline Racional-legal & $\begin{array}{l}\text { Mensageiro Comum } \\
\text { Meios de Comunicação Social } \\
\text { Autoridade Formal } \\
\text { Associação Voluntária }\end{array}$ & 3 & 5 & 3,5 \\
\hline Profissional & Todos os Mecanismos & 4 & 4 & 5 \\
\hline $\begin{array}{l}\text { Qualquer dos dois } \\
\text { modelos primeiros }\end{array}$ & Escolha Inadequada & 2 & 2 & 2 \\
\hline Paternalista & Quaisquer mecanismos & 1 & 1 & 1 \\
\hline
\end{tabular}

T A B E L A 3

Gradação do Contrôle Social para Diferentes Tipos de Familias Segundo Combinações Diferentes de Alguns Mecanismos de Enlace

\begin{tabular}{l|c|c|c}
\hline \multirow{2}{*}{ Mecanismos de Enlace } & Tipos de Familias \\
\cline { 2 - 4 } & $\begin{array}{c}\text { Resistentes } \\
\text { (1) }\end{array}$ & $\begin{array}{c}\text { Não Organizadas } \\
\text { (2) }\end{array}$ & $\begin{array}{c}\text { Conformes } \\
\text { (3) }\end{array}$ \\
\hline
\end{tabular}

Perito Partícipe ou Lider Natural mais Agêncta Local e Função Delegada
(3)
(1)

3
(1)

4
Mensageiro Comum e Associação Voluntária

Associacão Voluntária ou Autoridade Formal
(2)

3
(1)

2

(3)

5

(2)
(2)

5
(3)

4

6

NOTA: A soma dos pesos (entre parênteses) dá o grau atingindo nas diferentes combinações. O grau maior significa maior contrôle social e, em consequiência, melhor rendimento (objetivos atingidos). Assim somando "Tipos de Familias Resistentes" mais o primeiro conjunto de "Mecanismos de Enlace", teremos: $1+3=4$. 
PILON, A. F. - O problema metodológico em educação sanitária. Rev. Saúde públ., S. Paulo, 2(2) :216-225, dez. 1968.

T A B E L A 4

Gradação do Contrôle Social para Diferentes Tipos de Famílias Dentro de Núcleos de Vizinhança Opostos Segundo os Mecanismos de Enlace

\begin{tabular}{|c|c|c|c|c|c|c|c|c|c|c|c|c|}
\hline \multirow{3}{*}{$\begin{array}{l}\text { Mecanismos } \\
\text { de } \\
\text { Coordenação }\end{array}$} & \multicolumn{12}{|c|}{ Nücleos de Vizinhanca } \\
\hline & \multicolumn{6}{|c|}{$\begin{array}{l}\text { Favoráveis (3) } \\
\text { Tipos de }\end{array}$} & \multicolumn{6}{|c|}{$\begin{array}{l}\text { Desfavoráveis (1) } \\
\qquad F a m i l i a s\end{array}$} \\
\hline & 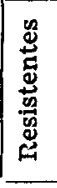 & (1) & 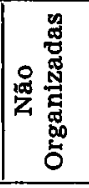 & (2) & 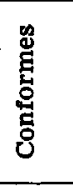 & (3) & 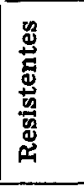 & (1) & 兽 & (2) & $\begin{array}{l}\text { : } \\
\text { : } \\
\text { : } \\
\text { : }\end{array}$ & (3) \\
\hline $\begin{array}{l}\text { Líder Natural mais Agência } \\
\text { Local }\end{array}$ & (3) & 7 & (2) 7 & & (2) 8 & 3 & (1) 3 & & (1) 4 & & (1) & 5 \\
\hline $\begin{array}{l}\text { Perito Partícipe mais Agên- } \\
\text { cla Local e Função Dele- } \\
\text { gada }\end{array}$ & (2) & 6 & (1) & & (1) & 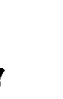 & (3) & & (2) & & (2) & 6 \\
\hline $\begin{array}{l}\text { Mensageiro Comum ou Meios } \\
\text { de Comunicação Social } \\
\text { mais Associaçōes Voluntá- } \\
\text { rias ou Autoridade Formal }\end{array}$ & (1) & 5 & (3) & & (3) & 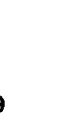 & (1) & & (3) & & (3) & 7 \\
\hline
\end{tabular}

NOTA: Para compreensão desta Tabela, seguir as instruç̃es da Tabela 3.

cia, a escolha recairá na combinação mais econômica. Isto dependerá da escolha racional dos recursos disponíveis. Não deverá ser colocado um perito participante junto a uma agência tipo relaçōes huma. nas ou profissional quando o mesmo resultado poderá ser fàcilmente alcançado por uma organização racional-legal (já existente) operando junto a grupos conformes da comunidade. Dificilmente uma organização racional-legal poderá, por outro lado, lidar com líderes naturais, uma vez que não é possível conseguir sua confiança e colaboração através de normas e regulamentos. Eis porque os auto. res relacionam os mecanismos aos modelos administrativos.

'As conseqüências mais notáveis dessa tríplice ou quádrupla correlação residem precisamente na metodologia. Assim, verificamos que melhores resultados serão obtidos por uma agência profissional uti- lizando um líder de um núcleo já favo. rável a seus propósitos como mecanismo de enlace, enquanto em outro núcleo antagônico pouco poderá ser conseguido através do líder natural, que, na expressão de Litwak \& MEYer ${ }^{1}$, passa a funcionar, nesse caso, como para-raios, atraindo as mensagens sem passá-las adiante. Aqui a solução será alcançada atra. vés do perito participante, que recebe treinamento especial para lidar com populaçōes hostis, no sentido de mudança cultural, através de sua integração ao grupo e utilizando os recursos locais (1). Quando, porém, a vizinhança é favorável, mas apenas a família resistente, o líder do bairro continuará o melhor mecanismo, sendo contraproducente o emprêgo do perito, que onerará ainda desnecessàriamente nosso programa.

(1) “Inner Resources Approach" (ROSS '; 1955). 
PILON, A. F. - O problema metodológico em educação sanitária. Rev. Saúde públ., S. Paulo, Z(2) :216-225, dez. 1968.

\author{
T A B E L A $\mathbf{5}$
}

Gradação do Contróle Social para Diferentes Tipos de Familias Dentro de Núcleos de Vizinhanças Opostos Segundo os Mecanismos de Enlace e o Estílo Administrativo da Agêncla (Modelos de Estrutura Burocrática)

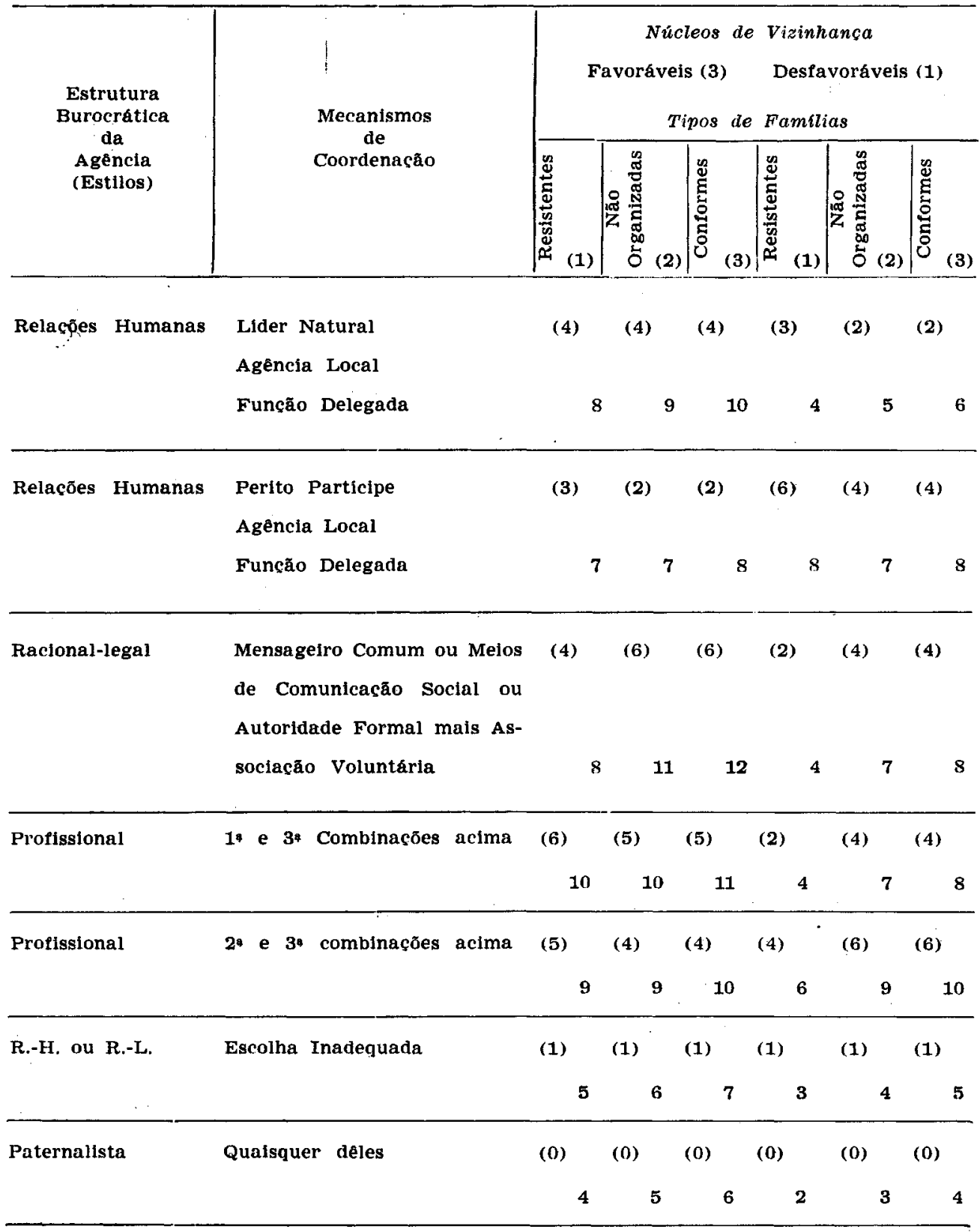

NOTA: Para compreensão desta Tabela, seguir as instruçōes da Tabela 3. 
PILON, A. F. - O problema metodológico em educação sanitária. Rev. Saúde públ., S. Paulo, $2(2): 216-225$, dez. 1968.

Talvez os autores apresentem fatos sabidos. Porém o mérito da teoria é justamente a sistematização do conhecimento, tornando-o operacional. $\mathrm{E}$, mais do que nunca, é oportuna, quando se discute ainda qual o "melhor" método de educação sanitária nos órgãos de saúde pública $\mathrm{e}$ até nas escolas especializadas.

\section{$S$ U M M A R Y}

In any public or private social-addressed programme arises the question of how to coordinate agency-client relationships, in order to obtain the best results, in terms of agency's policy and aims and people's interests and needs. Two american sociologists, Litwak and Meyer, of Michigan University, postulate that this coordination is a function of the degree of social distance between agency and clientele. Thus "maximum social control is most likely to occur when coordinating mechanisms develop between bureaucratic organizations and external primary groups that balance their relationships at a middle position of social distance where they are not too intimate and not isolated from one another". These mechanisms are 1) the detached expert approach; 2) the opinion leader approach; 3 ) the settlement house approach; 4) the voluntary association approach; 5) the common messenger approach; 6) the mass media approach; 7) the formal authority approach and 8) the delegated function approach, all of them with differential power of initiative, intensity, focused expertise and coverage. All the different mechanisms of coordination should be used according to the degree of social distance between agency and clientele, which means that in dealing with external groups the agency must decide whether they are supporting ones (same values of the agency, informed and organized), resistent ones (deviant values and organized), or a mixture tipe (some deviant, some conforming or with the desired values, but not organized or lacks knowledge). The agencies which are to deal with groups must not just select the appropriate mechanisms, but ought to have themselves the desired structure to facilitate the coordination, according to the cases. Besides that, the objectives of their programmes shall be analised, whether they are pure informative-content objectives or culture change-content objectives. We believe that the "balance theory of coordination between bureaucratic organizations and external primary groups", as the authors call it, is an important contribution to the intended integration of the Social Sciences with the Educational and Administrative ones. In the field of Health Education methodology, it gives a more sound criterium to choose the appropriate methods in dealing with people, according to the content of our message and the characteristics of the clientele concerned, without forgeting the bureaucratic structures of our own agencies.

\section{REFERENCIAS BIBLIOGRAFICAS}

1. LITWAK, E. \& MEYER, H. J. - $A B a-$ lance Theory of Coordination Between Bureaucratic Organizations and External Primary Groups. Ann Arbor, University of Michlgan. s.d. (Mimeografado).

2. PEREIRA, L. - A escola numa área metropolitana. São Paulo, Pioneira/Ed. USP, 1967.

3. ROSS, M. G. - Community Organization. New York, Harper \& Brothers, 1955. 